\title{
Attentional bias in Internet users with problematic use of social networking sites
}

\author{
MARIA NIKOLAIDOU*, DANAË STANTON FRASER and NEAL HINVEST \\ Department of Psychology, University of Bath, Bath, UK
}

(Received: June 24, 2019; revised manuscript received: September 18, 2019; accepted: October 20, 2019)

\begin{abstract}
Background and aims: Evidence from the field of addictive disorders suggests that attentional bias for stimuli related to a substance or activity of abuse (e.g., gambling) exacerbates the addictive behavior. However, evidence regarding attentional bias in PIU is sparse. This study aims to investigate whether individuals who express problematic tendencies toward social networking sites (SNS), a subtype of PIU, show attentional bias for stimuli associated with social media. Methods: Sixty-five participants performed Visual Dot-Probe and Pleasantness Rating Tasks containing SNS-related and matched control images during eye movements were recorded, providing a direct measure of attention. Participants were assessed on their levels of SNS Internet use (ranging from problematic to nonproblematic) and their levels of urges to be online (high vs. low). Results: Problematic SNS users and, in particular, a subgroup expressing higher levels of urges to be online showed an attentional bias for SNS-related images compared to control images. Conclusion: These results suggest that attentional bias is a common mechanism associated with problematic Internet use as well as other addictive disorders.
\end{abstract}

Keywords: social networking sites, problematic Internet use, attentional bias, urges to be online

\section{INTRODUCTION}

Problematic Internet use (PIU) has been found to resemble substance-related and other addictive disorders on a behavioral (Bielefeld et al., 2017; Grant, Potenza, Weinstein, \& Gorelick, 2010) and neurobiological level (Dong, Huang, \& Du, 2011). In addition, the evidence is suggestive of a comorbidity between them (Sussman, Lisha, \& Griffiths, 2011). Furthermore, research suggests that different addictive disorders are associated with some unique features, but that they also share vital underlying mechanisms (Shaffer et al., 2004).

Davis (2001) suggests that PIU consists of two distinct forms: specific and general. General refers to a more global set of behaviors, whereas specific involves engagement with specific Internet applications such as social networking sites (SNSs). General PIU has been a highly debated concept with researchers questioning whether or not the Internet per se is a source of the problematic behavior or whether it is through applications of the Internet that people show these problematic behaviors (Griffiths, 2010; Shaffer, Hall, \& Vander Bilt, 2000; Yellowlees \& Marks, 2007). This argument has led to the suggestion that specific application such as SNS use should be assessed instead of general PIU (Griffiths, Kuss, \& Demetrovics, 2014). Thus, following these recommendations, this study focuses on SNS use.

SNSs include online applications, such as Facebook, Twitter, LinkedIn, etc., which aim to provide a platform for social interactions among their users. A lot of research in the field have been devoted to identifying patterns of usage and trait characteristics of problematic and non-problematic
SNS users (Casale \& Fioravanti, 2018; Casale, Fioravanti, \& Rugai, 2016; Frost \& Rickwood, 2017). However, there is little insight into the behavioral characteristics, particularly of those individuals who lose control over their SNS use and develop problematic SNS use. This is also reflected within the prevalence rates, which varied significantly across studies with figures fluctuating from $4.5 \%$ to $47 \%$ reported being addicted to Facebook (Bányai et al., 2017; Jafarkarimi, Sim, Saadatdoost, \& Hee, 2016). In addition, there is emerging evidence that more intense use of SNS is associated with addictive symptoms and other addictive behaviors such as shopping and food addiction (Müller et al., 2016; Tang, Koh, \& Gan 2017). Conducting research investigating whether problematic SNS users show addictionlike tendencies such as biases toward their preferred specific applications will enrich our understanding of the potential mechanisms involved in the generation of this debatable emerging disorder.

One of the prominent characteristics of substance-related and addictive disorders is the power that substance-related stimuli have to influence and induce substance-seeking behavior (Field \& Cox, 2008), through a mechanism that enhances attentional allocation to those cues. This process has been termed attentional bias, and it has been argued that this bias is either causing or indicating the underlying mechanisms related to substance-seeking behavior (Robbins \& Ehrman, 2004). According to incentive sensitization

* Corresponding author: Maria Nikolaidou, PhD; Department of Psychology, University of Bath, 10 West, Bath BA2 7AY, UK; Phone: +44 122538 4233; E-mail: mn325@bath.ac.uk

This is an open-access article distributed under the terms of the Creative Commons Attribution-NonCommercial 4.0 International License, which permits unrestricted use, distribution, and reproduction in any medium for non-commercial purposes, provided the original author and source are credited, a link to the CC License is provided, and changes - if any - are indicated. 
theory (Robinson \& Berridge, 1993, 2001), through the processes of classical conditioning, stimuli related to substances of abuse are associated with the incentive motivation of substances and thus elicit conditioned responses. The increase in incentive salience means that substance-related stimuli are perceived as highly salient and capture attention (Robinson \& Berridge, 1993). Although the assumption on which this theory was based when first developed pertained to psychostimulant drugs (amphetamine, cocaine, etc.), there is now evidence that the same processes can explain the cycle of behavioral addictions, such as in pathological gambling (Brevers et al., 2011; Honsi, Mentzoni, Molde, \& Pallesen, 2013), shopping addiction (Jiang, Zhao, \& Li, 2017), online pornography (Pekal, Laier, Snagowski, Stark, \& Brand, 2018), and therefore could also be applicable to problematic SNS Internet use.

Moreover, research from the field of addiction has found that craving levels and evaluative bias (the bias of perceiving substance-related stimuli as highly pleasant) are associated with attentional bias and as a consequence with substance-seeking behavior (Field \& Cox, 2008; Field, Mogg, \& Bradley, 2004). Although the role of craving and evaluative bias in drug-seeking behavior is well established, there is a lack of studies assessing their role in the field of problematic SNS Internet use. Franken (2003) proposed that the relationship between attentional bias and craving is reciprocal such that attentional bias can lead to increased cravings and drug-seeking behavior and the increased craving can lead to attentional bias and drug-seeking behavior (Franken, 2003). Similarly, Pekal et al. (2018) found that there was a relationship between attentional bias and symptom severity of Internet pornographic disorder, which was partially mediated by indicators for cue-reactivity and craving. Thus, in this study, levels of urges to be online and evaluative bias were assessed and compared across SNS Internet users. Urges to be online were conceptualized similar to craving levels and indexed as an increased urge to pursue the activity in question.

Following the principles of incentive sensitization theory, it was hypothesized that individuals with problematic SNS Internet use would show attentional and evaluative biases for SNS images. Moreover, it was also hypothesized that for problematic SNS Internet users, there would be a positive correlation between levels of urges to be online, attentional, and evaluative biases for SNS images.

\section{METHODS}

\section{Participants}

One hundred and twenty-six participants filled in a battery of questionnaires on an online data collection website (Bristol Online Survey, now called Online Survey). The participants were recruited through advertisements placed within the University of Bath. From those, a convenience sample of 65 participants (41 females) between the ages of 18 and 29 years [mean $(M)$ age $=20.1$ years, standard deviation $(S D)=2.7]$ were recruited to conduct the lab-based experiment (Dot-Probe Task). Participants were selected based on their responses on the Addiction-Engagement Questionnaire (AEQ), aiming to have an equal number of participants in each of the groups of SNS users (further details are provided below). All participants had normal or corrected-to-normal vision and were recruited from the UK. All participants received $£ 10$ reimbursement.

\section{Measures}

Addiction-Engagement Questionnaire (AEQ). The AEQ is a 24-item self-report assessment of the severity of PIU and consists of positive and negative statements. Respondents rate each item on a 7-point Likert scale (ranging from $1=$ completely agree to $7=$ completely disagree . The AEQ consists of two factors: addiction and engagement with scores ranging from 12 to a maximum of 84 for each factor. The addiction factor consists of 12 items, 7 of which relate to areas termed to be the "core" criteria of addiction (behavioral salience, conflict, relapse and reinstatement, and withdrawal symptoms) and similarly, the engagement factor consists of 12 items, 2 of which relate to what have been termed "peripheral" criteria of addiction (cognitive salience and euphoria).

In this study, the latest version of the scale previously used to assess behavioral patterns of a specific type of massively multiplayer online role-playing game: Asheron's Call (Charlton \& Danforth, 2007) was adapted and each item reworded with reference to SNS (e.g., "I sometimes neglect important things because of an interest in SNS" and "My social life has sometimes suffered because of my SNS Internet use").

Following the validated classification (Charlton \& Danforth, 2007, 2010; Metcalf \& Pammer, 2011), participants were assigned to each group based on their responses to the core and peripheral criteria on the AEQ. More specifically, problematic SNS Internet users had to respond positively to at least four out of the seven core criteria related to the addiction factor. In addition, high SNS engagers had to respond positively to one or two of the peripheral criteria about the engagement factor and three or less of the core criteria related to the addiction factor. The non-problematic SNS Internet users had to have negative responses in all of the seven cores and the two peripheral criteria. To indicate positive and negative responses, the items with the core and peripheral criteria of addiction were dichotomized (cut-off point 4), such that higher scores $(5,6,7)$ were associated with positive responses and lower $(3,2,1)$ with negative ones. The Cronbach's $\alpha$ coefficient was .80 .

Questionnaire on Internet Use Urges (QIUU). The QIUU is a 10-item self-report questionnaire assessing the severity of urges to be online. Respondents rate each item on a 7-point scale (ranging from $1=$ completely disagree to 7 = completely agree). The QIUU was adapted from the original Questionnaire on Smoking Urges-Brief (Cox, Tiffany, \& Christen, 2001; Tiffany \& Drobes, 1991). To assess levels of urges to be online, each item was reworded concerning online activity. For example, a statement such as "I have the desire for a cigarette right now" was reworded to "I have the desire to be online right now." The wording "online" has been selected as a means to 

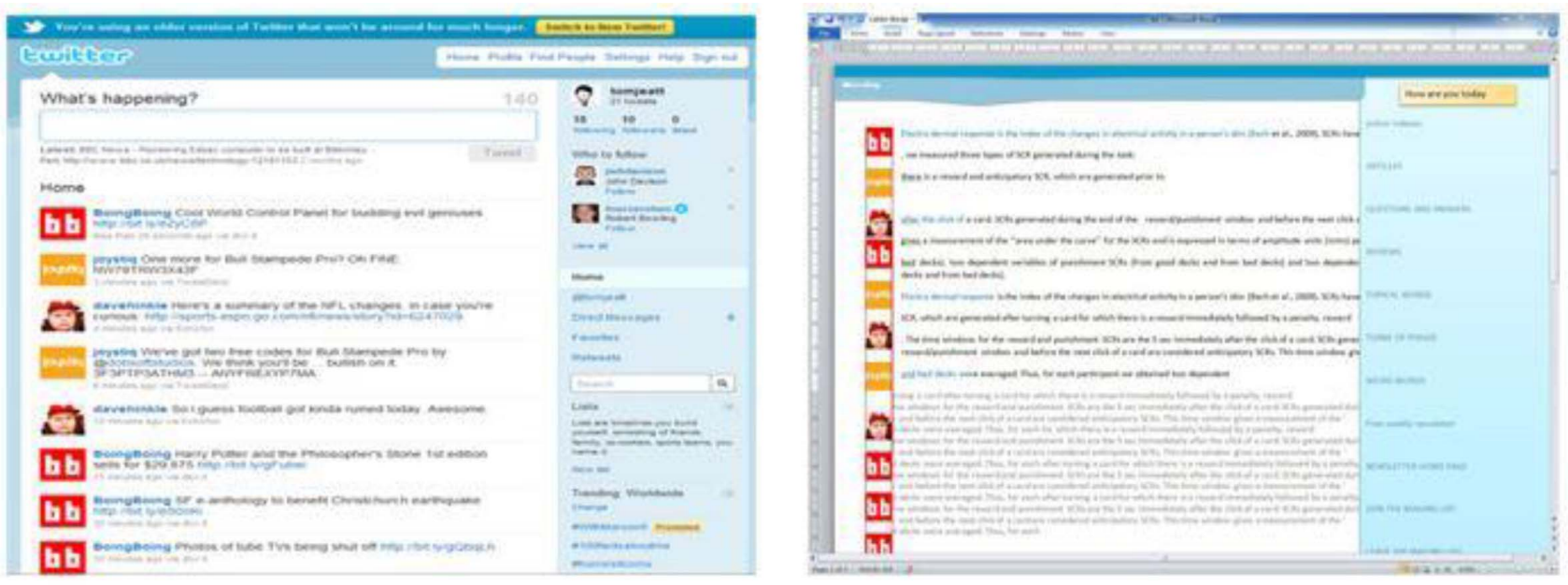

Figure 1. Presentation of SNS-related stimulus (Twitter website) on the left, matched with control-computer-related stimulus on the right (PowerPoint-generated image)

reflect the online component of SNS use. The Cronbach's $\alpha$ coefficient was .94 .

\section{Pictorial stimuli}

SNS-related stimuli consisted of pictorial color images containing general SNS-related activities (e.g., Facebook, Twitter, and Google ${ }^{+}$websites) and SNS-related logos (Facebook, Twitter, LinkedIn logos, etc.), which were retrieved from a Google image search. To obtain the most relevant images as sample stimuli, we retrieved a total of 40 SNS-related images. Twenty individuals (who did not participate in the study) rated all images on a 10-point scale according to their relatedness to the SNS (ranging from $1=$ not at all related to $10=$ very related $)$. From the 40 images including various SNS-related images, 15 were selected as the most relevant SNS images (based on the highest scores received). SNS-related stimuli consisted of pictorial color images. These 15 SNS images were matched with control images. Two types of control images were generated. One type referred to as the control-computerrelated images (see Figure 1), which were visually very similar to SNS-related images. These control-computer images are associated with the offline environment (familiar visual images you see when working on the computer offline). The other type of control images shared similar lower visual information with SNS-related and SNS logorelated images. However, they had no visual reference to the online environment or computer characteristics and were termed control non-computer images. These types of images were generated to control for the possibility that individuals who might show an attentional bias for SNS-related stimuli might also indicate a preference for computer-related stimuli, as computers are commonly used as a medium for being online. The size of the pictures was $5.5-\mathrm{cm}$ wide and $11-\mathrm{cm}$ high, and the distance between the inner edges of each picture in each pair was $3 \mathrm{~cm}$ (visual angle of $1^{\circ}$ between the fixation position and the inner side of each picture). Examples of the stimuli are presented in Figures 1-3.

In addition, 45 neutral pictures (everyday objects such as a cup, clock, umbrella, etc.) were taken from the
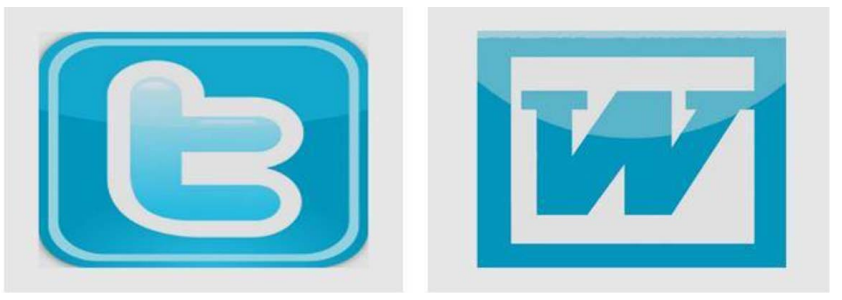

Figure 2. Presentation of SNS-related stimulus (logo) on the left, matched with control stimulus on the right

International Affective Picture System database (Lang, Bradley, \& Cuthbert, 2008) and used in fillers and practice trials. These images were shown side by side in a similar way to the other trials.

\section{Visual Dot-Probe Task - Eye-tracking}

A computational version of the Visual Dot-Probe Task (MacLeod, Mathews, \& Tata, 1986) was used. Each trial started with the fixation cross ("+"), which was presented centrally on the computer screen for $1,000 \mathrm{~ms}$, followed by the presentation of the pair of images side by side for $2,000 \mathrm{~ms}$. Immediately after the offset of the images, a probe (dot, ".") appeared either on the left- or right-hand side of the computer screen (the distance between the two probe positions was $11.5 \mathrm{~cm}$ ) replacing one of the images. The task required participants to respond as quickly and as accurately as possible by pressing one of the designated keys on the keyboard related to the location where the probe appeared on the screen. The dot remained on the screen until participants made a response, indicated by pressing one of the response buttons on the keyboard (" $\mathrm{m}$ " when the dot appeared on the right side of the computer screen and " $z$ " when it appeared on the left side). A participant's response terminated the trial, and the next one began 2,000 ms later. There were 8 practice trials and 80 experimental trials (60 SNS-related and 20 filler trials). During the 60 SNS-related trials (which were the trials where the pair of images consisted of SNS and matched controls), each of the 15 SNS-related images was 

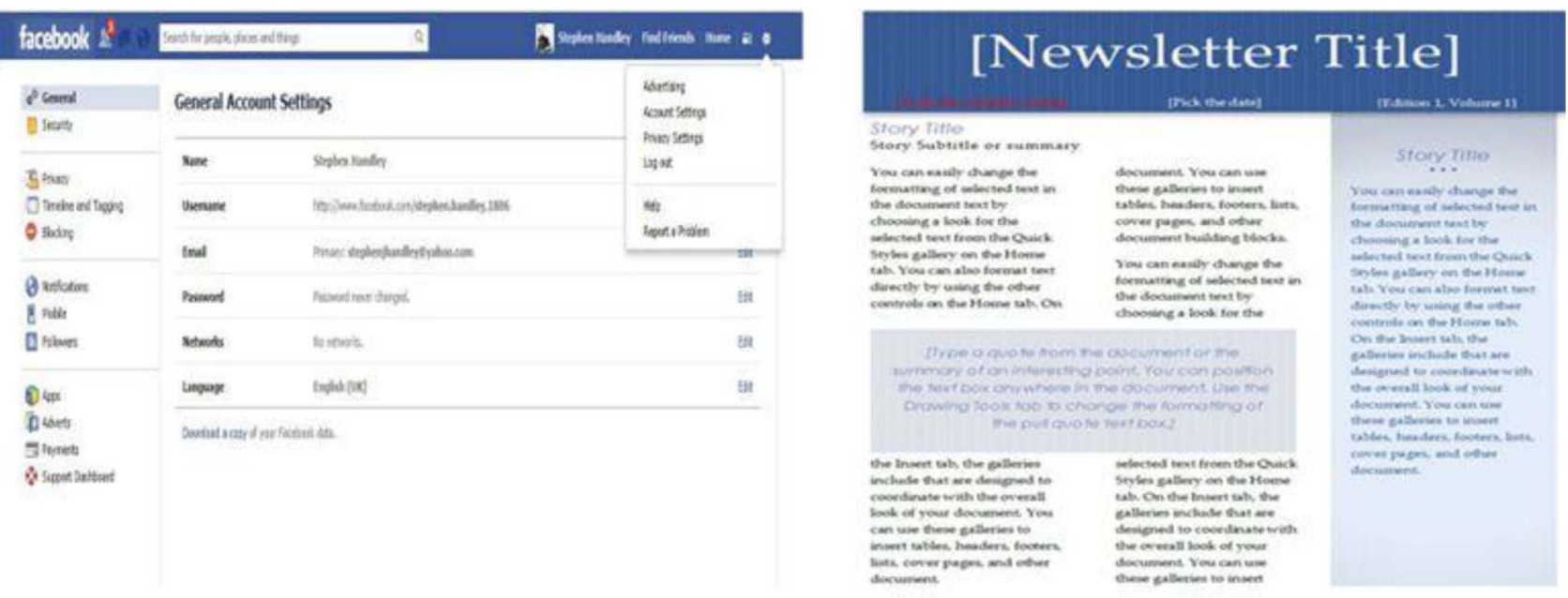

Figure 3. Presentation of SNS-related stimulus (Facebook website) on the left, matched with control non-computer-related stimulus on the right

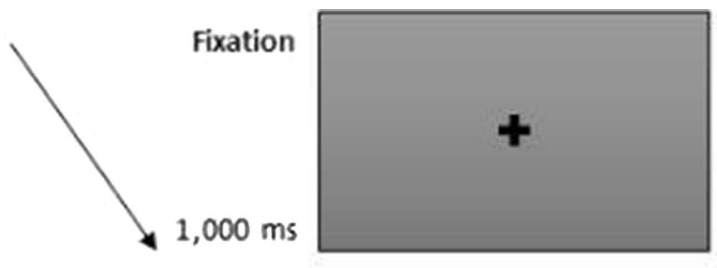

Displayed for
$1,000 \mathrm{~ms}$

Displayed for

$2,000 \mathrm{~ms}$

Displayed until

' $m$ ' or ' $z$ '

response

Trial end.

Next trial starts

after $2,000 \mathrm{~ms}$

Figure 4. Example of an experimental trial in the Visual Dot-Probe Task

presented four times and appeared twice on the left side and twice on the right side of the screen. Moreover, they were matched and counterbalanced in half of the trials with control-computer and the other half with control noncomputer and symbols. SNS-related and filler trials were pseudorandomized and presented in the same order for all participants (Figure 4).

\section{Pleasantness Rating Task}

The Pleasantness Rating Task was generated with E-prime 2.0 Professional software (Psychology Software Tools,
Pittsburgh, PA, USA). The main requirement of this task was to rate the pleasantness of each of the 40 images (15 SNS and 25 control images), which were presented in the Dot-Probe Task, except the neutral images, which were used for the practice and filler trials. Following the presentation of each image $(2,000 \mathrm{~ms})$, participants rated on a 7-point scale how pleasant each image appeared to them (ranging from $1=$ not pleasant to $7=$ very pleasant) by pressing one of the seven corresponding keys on the keyboard (numbers 1-7). The size of the pictures was $15.5-\mathrm{cm}$ wide and 11-cm high, and there was a 2,000-ms intertrial interval. 


\section{Preparation of eye movement data}

Eye movements were only analyzed for the 60 SNSrelated trials. Dwell time was calculated based on the amount of time participants spent fixating (summing the duration of each fixation) on both images and the central location (between the area of the image) for each trial. The average time participants spent looking at these three areas altogether was analyzed first and trials excluded where there were excessive missing data (no recorded eye movements or fixations were more than $3 S D$ s above the sample mean). Analyzable data was recorded in $90.2 \%$ of the SNS-related trials. A one-way analysis of variance (ANOVA) revealed that there was no difference for the non-analyzable trials among the groups of SNS Internet users $F(2,63)=1.54, p=.22$. Trials with error responses made up $1 \%$ of the total trials and were included in the final analysis as they represented real eye movements. The fixation duration was analyzed for each of the images presented side by side. Longer fixation duration indicated an attentional bias for that specific image.

\section{Procedure}

Participants were provided with information on the study's aims and processes, they had the opportunity to ask any questions, and they granted consent. Once they agreed to take part, they completed a questionnaire comprising the AEQ online. Based on the selection criteria outlined above, a sample of SNS Internet users was invited to participate in the second phase of the experiment, which took place in the Department of Psychology laboratories at the University of Bath. Upon arrival, participants were given information about the experimental procedures and provided informed consent. Next, the participants sat comfortably in a chair at a $70-\mathrm{cm}$ distance (approximately) from a computer display where they performed the two computer-based tasks. At the beginning of the testing procedure, eye tracker calibration was conducted. The participants then completed the Dot-Probe Task and were explicitly instructed to try to stay as still as possible throughout the experiment, to fixate on the cross at the start of each trial when it appeared on the screen, and to try not to blink while they viewed the cross and the pair of pictures. Then, they completed the Pleasantness Rating Task and a QIUU questionnaire. After completion of the survey, participants were fully debriefed and received a payment of $£ 10$. The total participation time took approximately $30 \mathrm{~min}$. Those participants who filled in the online questionnaires but were not selected for the second phase of the experiment had the opportunity to win a $£ 50$ Amazon voucher in a prize draw.

\section{Statistical analyses}

Initially, gender and age differences between the groups were checked with one-way ANOVAs. Two (image type SNS vs. control) by three (SNS Internet use groups problematic, high engagers, and non-problematic SNS Internet users) mixed ANOVAs assessed the duration fixation and pleasantness ratings, followed up with post-hoc tests (Bonferroni correction) to identify the differences between the groups. Further analyses were conducted for trials where SNS images were matched with controlcomputer-related images and for trials where they were paired with non-computer-associated images. The supplementary analysis was conducted to assess whether there were differences in behavioral outcomes related to each type of control stimuli.

In addition, Pearson's correlation coefficients were conducted to assess the relationship between biases (cognitive and evaluative) and motivational levels for each SNS Internet users.

\section{Ethics}

The study procedures were carried out by the Declaration of Helsinki. The Institutional Review Board of the Department of Psychology, University of Bath, approved this study. All participants were informed about the study, and all provided informed consent.

\section{RESULTS}

Table 1 revealed no differences between groups regarding age and gender.

\section{Dwell time for SNS Internet users (SNS compared to computer and control non-computer images)}

A significant interaction between image type and group, $F(2,62)=3.94, p=.02, \eta p^{2}=.11$. The main effect of image type, $F(1,62)=3.40, p=.07$ and group, $F(2,62)=0.28$, $p=.76$ was non-significant. Further analysis based on the significant interaction revealed that problematic SNS Internet users spent more time looking at the SNS compared to the control images, $t(15)=2.28, p=.038,95 \%$ CI [6.80, 126.20]. However, this was not evident for high engagers, $t(24)=0.97, p=.34$ and non-problematic SNS Internet users $t(23)=-1.18, p=.25$. Non-problematic SNS Internet users fixated on control-related less compared SNS images, $t(38)=-2.17, p=.004,95 \%$ CI $[-185.36,-6.39]$ (Figure 5).

\section{Supplementary analysis for computer condition (SNS compared to computer control images)}

Dwell time. The results revealed no significant main effects of image type, $F(1,62)=1.04, p=.31$, group effect, $F(2,62)=0.07, p=.93$, or interaction between image type and group, $F(2,62)=0.29, p=.75$.

Supplementary analysis for non-computer condition (SNS compared to control non-computer images)

Dwell time. The results revealed a significant main effect of image type, $F(1,62)=9.87, p=.003, \eta p^{2}=.14$ and interaction between image type with group, $F(2,62)=$ 4.75, $p=.012, \eta p^{2}=.13$. The group effect was nonsignificant, $F(2,62)=0.39, p=.67$. Post-hoc tests revealed that problematic SNS Internet users spent more time looking 
Nikolaidou et al.

Table 1. Demographic, questionnaire, and performance scores of SNS Internet use groups

\begin{tabular}{|c|c|c|c|c|c|}
\hline & PSIU $(n=16)$ & HESU $(n=25)$ & NPSIU $(n=24)$ & \multirow{2}{*}{$\begin{array}{l}\text { ANOVA } F \\
\text { value } / \chi^{2}\end{array}$} & \multirow{2}{*}{$\begin{array}{l}\text { Post-hoc comparisons } \\
\text { (Tukey's HSD and } \\
\text { Games-Howell) }\end{array}$} \\
\hline & Mean $(S D)$ & Mean $(S D)$ & Mean $(S D)$ & & \\
\hline Age (years) & 19.25 (1.39) & $21.08(2.94)$ & $20.92(2.9)$ & 2.68 & \\
\hline Gender $(\mathrm{M} / \mathrm{F})$ & $4 \mathrm{M} / 12 \mathrm{~F}$ & $10 \mathrm{M} / 15 \mathrm{~F}$ & $10 \mathrm{M} / 14 \mathrm{~F}$ & 1.31 & \\
\hline AEQ addiction & $56.13(10.92)$ & $39.20(7.30)$ & $18.62(6.39)$ & $107.97 * *$ & $\begin{array}{c}\text { PSIU > HESU, NPSIU; } \\
\text { HESU > NPSI }\end{array}$ \\
\hline $\begin{array}{l}\text { AEQ high } \\
\text { engagement }\end{array}$ & $60.25(10.61)$ & $56.88(8.99)$ & $37.21(10.66)$ & $33.66^{* *}$ & $\begin{array}{l}\text { PSIU > NPSIU; } \\
\text { HESU > NPSIU }\end{array}$ \\
\hline $\begin{array}{l}\text { Gaze dwell time for } \\
\text { SNS images }\end{array}$ & $652.88(160.15)$ & $641.88(173.32)$ & $612.42(119.25)$ & 0.40 & \\
\hline $\begin{array}{l}\text { Gaze dwell time for } \\
\text { control images }\end{array}$ & $546.38(111.91)$ & $613.16(164.24)$ & $642.25(151.06)$ & 2.04 & \\
\hline QIUU & $31.00(12.55)$ & $31.68(13.02)$ & $19.88(12.08)$ & $6.40 * *$ & $\begin{array}{l}\text { PSIU > NPSIU; } \\
\text { HESU > NPSIU }\end{array}$ \\
\hline $\begin{array}{l}\text { Pleasantness rating } \\
\text { of SNS Internet } \\
\text { images all trials }\end{array}$ & $3.80(0.48)$ & $3.58(0.56)$ & $3.52(0.60)$ & & \\
\hline $\begin{array}{l}\text { Pleasantness rating } \\
\text { of control images } \\
\text { all trials }\end{array}$ & $3.74(0.44)$ & $3.56(0.58)$ & $3.51(0.58)$ & & \\
\hline
\end{tabular}

Note. SD: standard deviation; SNS: social networking site; AEQ: Addiction and Engagement Questionnaire with subscales; PSIU: problematic SNS Internet users (four or more addiction criteria); HESU: high engagers SNS Internet users (three or fewer addiction criteria and one or two peripheral criteria); NPSIU: non-problematic SNS Internet users (none of the addiction or peripheral criteria); QIUU: Questionnaire on Internet Use Urges; ANOVA: analysis of variance; HSD: honestly significant difference. $* * p<.01$.

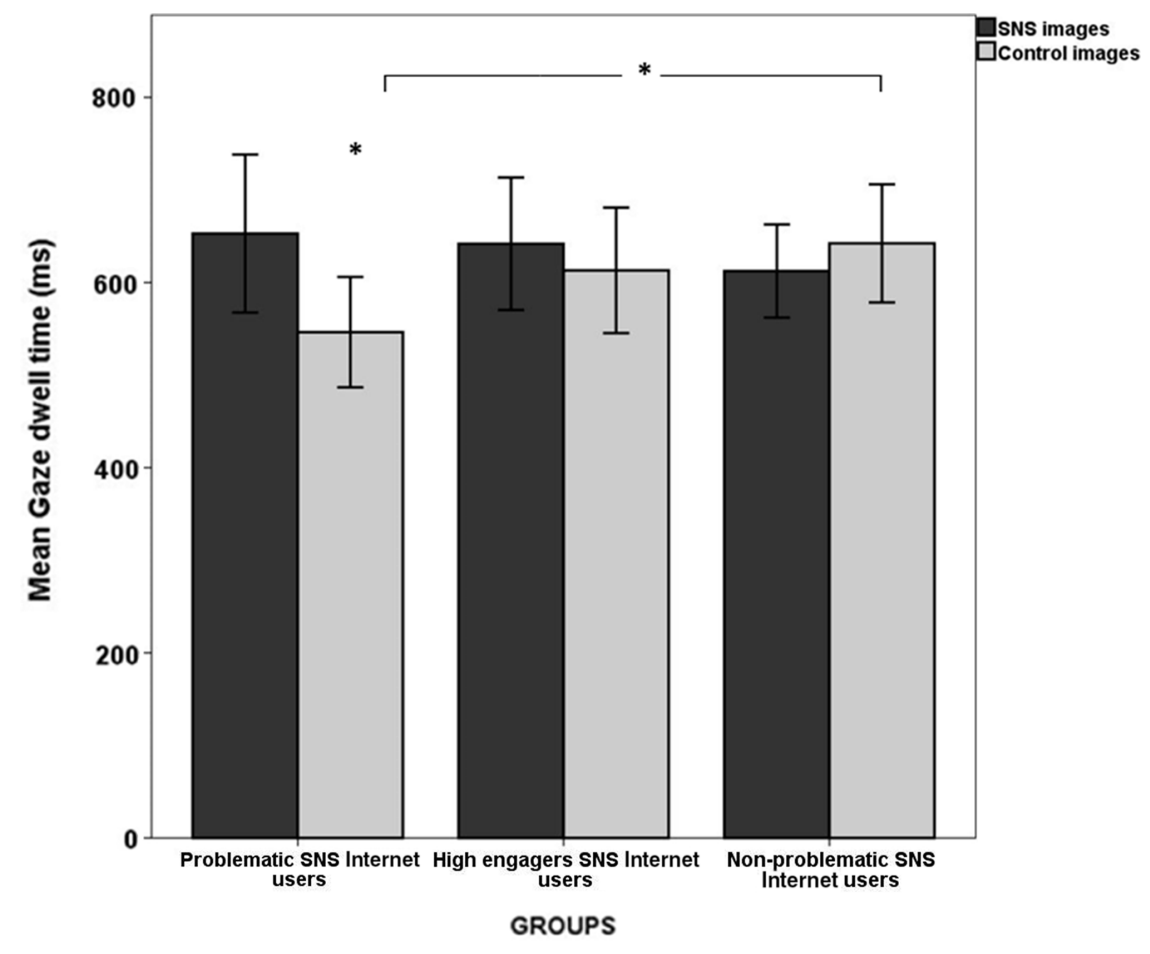

Figure 5. Mean gaze dwell time (in ms) on SNS and control images, shown separately for problematic, high engagers, and non-problematic SNS Internet users with CI error bars. ${ }^{*} p<.05$

at the SNS compared to control non-computer images, $t(15)=2.82, p=.013, d=1.45 .95 \%$ CI $[34.33,247.74]$ and this was also evident for high SNS engagers, $t(24)=2.20, p=.037, d=0.89,95 \%$ CI [4.13, 126.52] (Figure 6).
Pleasantness Rating Task: Stimulus valence measures (SNS compared to computer and control non-computer images)

The results revealed no significant main effect of image type, $F(1,62)=0.84, p=.36$, group effect, $F(2,62)=1.08$, 


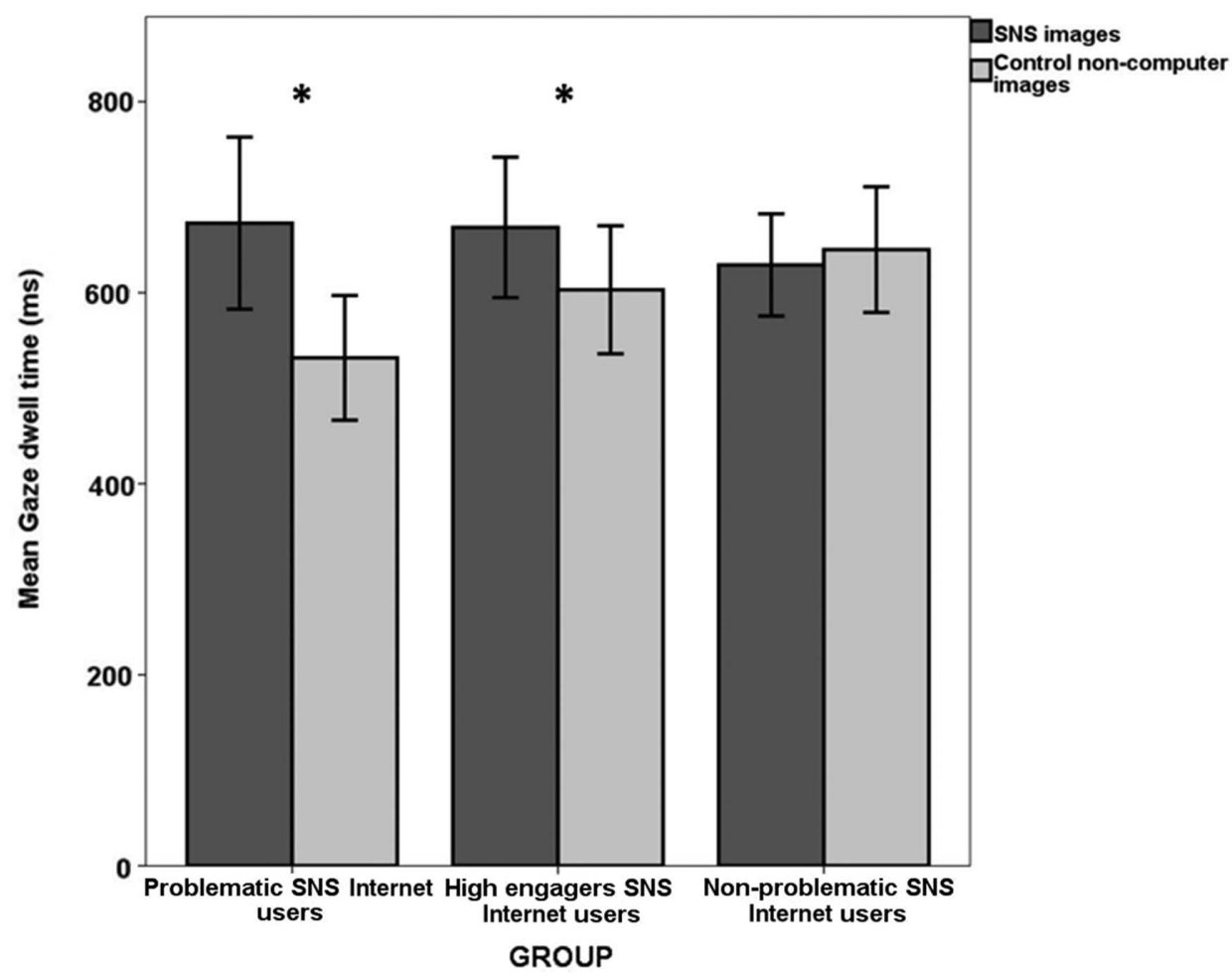

Figure 6. Mean gaze dwell time (in ms) on SNS and control non-computer images, shown separately for problematic, high engagers, and non-problematic SNS Internet users with CI error bars. ${ }^{*} p<.05$

Table 2. Pearson's correlation between dwell time, pleasantness ratings, and urges to be online for each SNS Internet users' group

\begin{tabular}{|c|c|c|c|}
\hline & Problematic SNS Internet users & High engagers SNS Internet users & Non-problematic SNS Internet users \\
\hline & Urges to be online & Urges to be online & Urges to be online \\
\hline Dwell time & $.703 * *$ & -.018 & .350 \\
\hline Pleasantness rating & -.354 & -.070 & .205 \\
\hline
\end{tabular}

Note. Values are correlation coefficients; bold coefficients are statistically significant (two-tailed).

$* * p<.01$.

$p=.35$, or interaction between image type and group, $F(2,62)=0.16, p=.85$.

Correlations between attentional, evaluative biases, and urge to be online for SNS Internet users

To conduct correlational analysis, the following calculations were made: (a) for the gaze dwell time, the mean dwell time spent on control images was subtracted from the mean dwell time spent on SNS images, and thus positive scores indicated a bias for SNS images; (b) for the evaluative bias, the mean pleasantness ratings for the controls was subtracted from mean pleasantness ratings for SNS images and thus positive scores reflected an evaluative bias for SNS images.

Table 2 revealed that there were significant positive correlations between attentional bias for SNS images with urges to be online, $r=.703, p=.002$ for the problematic SNS Internet users. No other associations were found.

\section{DISCUSSION}

This study revealed that individuals with problematic SNS Internet use showed an attentional bias for SNS-related images compared to control images. Moreover, when levels of urges to be online were assessed, problematic SNS Internet users showed a positive correlation between attentional bias for SNS-related images and urges to be online. These results are supportive of our hypotheses and are suggestive of commonalities between problematic SNS Internet use and established addictions in the mechanisms that have been suggested to account for the maintenance of the addiction cycle (Franken, 2003; Field \& Cox, 2008; Field, Munafò, \& Franken, 2009; Robinson \& Berridge, 1993, 2001). More specifically, the results of this study are in line with research from the field of substance addiction disorders, which has suggested that craving levels are associated with attentional bias (Field et al., 2004; Field, Mogg, Mann, Bennett, \& Brandley, 2013; Franken, 2003). Furthermore, they are also in accordance with similar 
evidence found in behavioral addictions, such as gambling, online gaming, and online pornography (Lorenz et al., 2013; McCusker \& Gettings, 1997; Metcalf \& Pammer, 2011; Pekal et al., 2018; van Holst et al., 2012).

However, when the analysis was performed based on the type of control images (control computer vs. control noncomputer), it was found that the group of problematic SNS Internet users did not show any bias for SNS-related stimuli in the control computer condition. In contrast, in the noncomputer condition, the analysis revealed an overall preference for SNS-related images as was shown by problematic and high engagers SNS Internet users. Therefore, it could be argued that control non-computer and symbol images are the best candidates for use in future research probing attentional bias in SNS Internet use, because computer-related images might be associated with online activities as they are deployed as a universal medium to be online and thus capture attention in a similar way to SNS-related images.

Moreover, problematic SNS Internet users did not perceive SNS images as being more pleasant. This is according to Robinson and Berridge's theory, which states that addiction is driven by an attentional bias due to "wanting" but not as a pleasantness bias toward "liking" the salient stimulus relevant to the problematic behavior. Furthermore, the results of this finding might also be due to the familiarity effect. There are reports that by 2020 the number of social media users in the UK alone will be 42.28 million individuals (Statista, 2018). This statistic indicates the level of familiarity with SNS-related images. Research into addiction compares similar behaviors between individuals who have not encountered substances of abuse and thus are unfamiliar with such stimuli compared to individuals with substance misuse who are familiar with such incentives (Field \& Cox, 2008).

Moreover, in this study, participants were explicitly asked to rate the attractiveness of SNS and control images, and this might have given rise to social desirability effects, especially for those who reported problematic SNS Internet behavior. Thus, future research should assess the implicit attitudes surrounding these stimuli. This may provide a better indication of how the perceived attractiveness of the stimuli can affect overt behavior using the Implicit Association Task and the Stimulus-Response Compatibility Task.

This was the first study that assessed attentional bias for online applications associated with social networking and as such, aimed to be inclusive of various forms. SNS consists of multiple applications such as Facebook, Twitter, LinkedIn, etc. In this study, we choose the most popular online applications at this point, and we generated stimuli associated with each application. However, there is the possibility that some SNS Internet users might predominantly use specific apps. This might have caused some SNS-related stimuli not to be as salient for some SNS Internet users who, for example, use SNS predominately for Facebook and not Twitter or LinkedIn. Thus, in the future, there is the necessity to identify groups of SNS Internet users who use predominately one SNS and assess whether differences in cognitive processes associated with attentional bias are more evident among these groups. However, this is a problem common to other fields (e.g., beer drinkers vs. wine drinkers); Facebook and Twitter are likely to be highly relevant to a vast population of social media users. In addition, as this was the first study that assessed attentional bias in SNS Internet use, we evaluated two types of control images (control computer and control non-computer). This was conducted to investigate whether control image type affects the overall allocation of attention. It was found that potentially control non-computer images captured attentional bias more in comparison to control computer images, which can inform future research. Even though conducting secondary analysis could reduce the power of the findings, the consistency of the research outcomes before and after the secondary analysis validates our research conclusions. Finally, even though the results of this study implicate that levels of urges to be online associate with attentional bias, there is no clear causal relationship between the two. Thus, further research is warranted in the field where direct manipulation of SNS use needs to be obtained and then assessment of its effects about levels of urges to be online, attentional, and evaluative biases carried out. This is by research from the field of addition where craving levels and evaluative bias have been found to associate with attentional bias and as a consequence with substance-seeking behavior (Field \& Cox, 2008; Kang et al., 2012).

In conclusion, the results of this study revealed that problematic SNS Internet users showed an attentional bias for SNS-related images, which is following theories from the field of addiction.

Funding sources: This study was funded by the University of Bath.

Authors' contribution: $\mathrm{MN}$ involved in study concept and design, analysis and interpretation of data, statistical analysis, obtained funding, and wrote the manuscript. DSF and NH involved in study supervision, study concept, and edited the manuscript.

Conflict of interest: The authors declare no conflict of interest.

\section{REFERENCES}

Bányai, F., Zsila, Á., Király, O., Maraz, A., Elekes, Z., Griffiths, M. D., Andreassen, C. S., \& Demetrovics, Z. (2017). Problematic social media use: Results from a large-scale nationally representative adolescent sample. PLoS One, 12, e0169839. doi:10.1371/journal.pone.0169839

Bielefeld, M., Drews, M., Putzig, I., Bottel, L., Steinbüchel, T., Dieris-Hirche, J., Szycik, G. R., Müller, A., Roy, M., Ohlmeier, M., \& Theodor Te Wildt, B. (2017). Comorbidity of Internet use disorder and attention deficit hyperactivity disorder: Two adult case-control studies. Journal of Behavioral Addictions, 6(4), 490-504. doi:10.1556/2006.6.2017.073

Brevers, D., Cleeremans, A., Bechara, A., Laloyaux, C., Kornreich, C., Verbanck, P., \& Noel, X. (2011). Time course of attentional bias for gambling information in problem gambling. Psychology of Addictive Behaviors, 25(4), 675-682. doi:10.1037/a0024201 
Casale, S., \& Fioravanti, G. (2018). Why narcissists are at risk for developing Facebook addiction: The need to be admired and the need to belong. Addictive Behaviors, 76, 312-318. doi:10.1016/.addbeh.2017.08.038

Casale, S., Fioravanti, G., \& Rugai, L. (2016). Grandiose and vulnerable narcissism: Who is at higher risk for social networking addiction? Cyberpsychology, Behavior, and Social Networking, 19(8), 510-515. doi:10.1089/cyber.2016.0189

Charlton, J. P., \& Danforth, I. D. W. (2007). Distinguishing addiction and high engagement in the context of online game playing. Computers in Human Behavior, 23(3), 1531-1548. doi:10.1016/j.chb.2005.07.002

Charlton, J. P., \& Danforth, I. D. W. (2010). Validating the distinction between computer addiction and engagement: Online game playing and personality. Behaviour and Information Technology, 29(6), 601-613. doi:10.1080/014492909034 01978

Cox, L. S., Tiffany, S. T., \& Christen, A. G. (2001). Evaluation of the brief Questionnaire of Smoking Urges (QSU-brief) in laboratory and clinical settings. Nicotine \& Tobacco Research, 3(1), 7-16. doi:10.1080/14622200020032051

Davis, R. A. (2001). A cognitive-behavioural model of pathological Internet use. Computers in Human Behavior, 17(2), 187-195. doi:10.1016/S0747-5632(00)00041-8

Dong, G., Huang, J., \& Du, X. (2011). Enhanced reward sensitivity and decreased loss sensitivity in Internet addicts: An fMRI study during a guessing task. Journal of Psychiatric Research, 45(11), 1525-1529. doi:10.1016/j.jpsychires.2011.06.017

Field, M., \& Cox, W. M. (2008). Attentional bias in addictive behaviours: A review of its development, causes, and consequences. Drug and Alcohol Dependence, 97(1-2), 1-20. doi:10.1016/j.drugalcdep.2008.03.030

Field, M., Mogg, K., \& Bradley, B. P. (2004). Cognitive bias and drug craving in recreational cannabis users. Drug and Alcohol Dependence, 74(1), 105-111. doi:10.1016/j.drugalcdep.2003. 12.005

Field, M., Mogg, K., Mann, B., Bennett, G. A., \& Bradley, B. P. (2013). Attentional biases in abstinent alcoholics and their association with craving. Psychology of Addictive Behaviors, 27(1), 71-80. doi:10.1037/a0029626

Field, M., Munafo, M. R., \& Franken, I. H. (2009). A meta-analytic investigation of the relationship between attentional bias and subjective craving in substance abuse. Psychological Bulletin, 135(4), 589-607. doi:10.1037/a0015843

Franken, I. H. A. (2003). Drug craving and addiction: Integrating psychological and neuropsychopharmacological approaches. Progress in Neuro-Psychopharmacology and Biological Psychiatry, 27(4), 563-579. doi:10.1016/S0278-5846(03) 00081-2

Frost, R., \& Rickwood, D. (2017). A systematic review of the mental health outcomes associated with Facebook use. Computers in Human Behavior, 76, 576-600. doi:10.1016/j.chb. 2017.08.001

Grant, J. E., Potenza, M. N., Weinstein, A., \& Gorelick, D. A. (2010). Introduction to behavioural addictions. The American Journal of Drug and Alcohol Abuse, 36(5), 233-241. doi:10.3109/00952990.2010.491884

Griffiths, M. D. (2010). The role of context in online gaming excess and addiction: Some case study evidence. International Journal of Mental Health and Addiction, 8(1), 119-125. doi:10.1007/s11469-009-9229-x
Griffiths, M. D., Kuss, D. J., \& Demetrovics, Z. (2014). Social networking addiction: An overview of preliminary findings. In K. P. Rosenberg \& L. C. Feder (Eds.), Behavioral addictions: Criteria, evidence, and treatment (pp. 119-141). London, UK: Academic Press.

Honsi, A., Mentzoni, R. A., Molde, H., \& Pallesen, S. (2013). Attentional bias in problem gambling: A systematic review. Journal of Gambling Studies, 29(3), 359-375. doi:10.1007/ s10899-012-9315-z

Jafarkarimi, H., Sim, A. T. H., Saadatdoost, R., \& Hee, J. M. (2016). Facebook addiction among Malaysian students. International Journal of Information and Education Technology, 6(6), 465-469. doi:10.7763/IJIET.2016.V6.733

Jiang, Z., Zhao, X., \& Li, C. (2017). Self-control predicts attentional bias assessed by online shopping-related Stroop in high online shopping addiction tendency college students. Comprehensive Psychiatry, 75, 14-21. doi:10.1016/j. comppsych.2017.02.007

Kang, O. S., Chang, D. S., Jahng, G. H., Kim, S. Y., Kim, H., Kim, J. W., Chung, S. Y., Yang, S. I., Park, H. J., Lee, H., \& Chae, Y. (2012). Individual differences in smoking-related cue reactivity in smokers: An eye-tracking and fMRI study. Progress in Neuro-Psychopharmacology and Biological Psychiatry, 38(2), 285-293. doi:10.1016/j.pnpbp.2012. 04.013

Lang, P. J., Bradley, M. M., \& Cuthbert, B. N. (2008). International Affective Picture System (IAPS): Affective ratings of pictures and instruction manual (Technical report A-8). Gainesville, FL: University of Florida.

Lorenz, R. C., Kruger, J. K., Neumann, B., Schott, B. H., Kaufmann, C., Heinz, A., \& Wustenberg, T. (2013). Cue reactivity and its inhibition in pathological computer game players. Addiction Biology, 18(1), 134-146. doi:10.1111/ j.1369-1600.2012.00491.x

MacLeod, C., Mathews, A., \& Tata, P. (1986). Attentional bias in emotional disorders. Journal of Abnormal Psychology, 95(1) 15-20. doi:10.1037//0021-843x.95.1.15

McCusker, C. G., \& Gettings, B. (1997). Automaticity of cognitive biases in addictive behaviours: Further evidence with gamblers. British Journal of Clinical Psychology, 36(4), 543-554. doi:10.1111/j.2044-8260.1997.tb01259.x

Metcalf, O., \& Pammer, K. (2011). Attentional bias in excessive massively multiplayer online role-playing gamers using a modified Stroop task. Computers in Human Behavior, 27(5), 1942-1947. doi:10.1016/j.chb.2011.05.001

Müller, K. W., Dreier, M., Beutel, M., Duven, E., Giralt, S., \& Wölfling, K. (2016). A hidden type of Internet addiction? Intense and addictive use of social networking sites in adolescents. Computers in Human Behavior, 55, 172-177. doi:10.1016/j.chb.2015.09.007

Pekal, J., Laier, C., Snagowski, J., Stark, R., \& Brand, M. (2018). Tendencies toward Internet-pornography-use disorder: Differences in men and women regarding attentional biases to pornographic stimuli. Journal of Behavioral Addictions, 7(3), 574-583. doi:10.1556/2006.7.2018.70

Robbins, S. J., \& Ehrman, R. N. (2004). The role of attentional bias in substance abuse. Behavioral and Cognitive Neuroscience Reviews, 3(4), 243-260. doi:10.1177/153458230527 5423

Robinson, T. E., \& Berridge, K. C. (1993). The neural basis of drug craving: An incentive-sensitisation theory of addiction. Brain 
Research. Brain Research Reviews, 18(3), 247-2911. doi:10.1016/0165-0173(93)90013-P

Robinson, T. E., \& Berridge, K. C. (2001). Incentive-sensitization and addiction. Addiction, 96(1), 103-114. doi:10.1046/j.13600443.2001.9611038.x

Shaffer, H. J., Hall, M. N., \& Vander Bilt, J. (2000). 'Computer addiction': A critical consideration. American Journal of Orthopsychiatry, 70(2), 162-168. doi:10.1037/h0087741

Shaffer, H. J., LaPlante, D. A., LaBrie, R. A., Kidman, R. C., Donato, A. N., \& Stanton, M. V. (2004). Toward a syndrome model of addiction: Multiple expressions, common etiology. Harvard Review of Psychiatry, 12(6), 367-374. doi:10.1080/10673220 490905705

Statista. (2018). Forecast of social network user numbers in the United Kingdom (UK) from 2015 to 2022 (in million users). The Statistics Portal. Retrieved October 12, 2018, from https:// www.statista.com/statistics/553530/predicted-number-of-socialnetwork-users-in-the-united-kingdom-uk/

Sussman, S., Lisha, N., \& Griffiths, M. (2011). Prevalence of the addictions: A problem of the majority or the minority?
Evaluation \& the Health Professions, 34(1), 3-56. doi:10.1177/0163278710380124

Tang, C. S.-K., Koh, Y. W., \& Gan, Y. (2017). Addiction to Internet use, online gaming, and online social networking among young adults in China, Singapore, and the United States. Asia-Pacific Journal of Public Health, 29(8), 673-682. doi:10.1177/1010539 517739558

Tiffany, S. T., \& Drobes, D. J. (1991). The development and initial validation of a Questionnaire on Smoking Urges. British Journal of Addiction, 86, 1467-1476. doi:10.1111/j.13600443.1991.tb01732.x

Van Holst, R. J., Lemmens, J. S., Valkenburg, P. M., Peter, J., Veltman, D. J., \& Goudriaan, A. E. (2012). Attentional bias and disinhibition toward gaming cues are related to problem gaming in male adolescents. The Journal of Adolescent Health, 50(6), 541-546. doi:10.1016/j.jadohealth. 2011.07.006

Yellowlees, P. M., \& Marks, S. (2007). Problematic Internet use or Internet addiction? Computers in Human Behavior, 23(3), 1447-1453. doi:10.1016/j.chb.2005.05.004 